\title{
Diagnósticos e intervenções de Enfermagem acerca da qualidade de vida da pessoa que vive com HIV: revisão integrativa
}

Nursing diagnoses and interventions regarding the quality of life of of people living with HIV: integrative review

Diagnósticos e intervenciones de Enfermería en relación con la calidad de vida de las personas que viven con el VIH: revisión integradora

Erick David Sarges Ribeiro ORCID: https://orcid.org/0000-0001-6950-5486 Universidade Federal do Maranhão, Brasil E-mail: edsarges@gmail.com

Laerte Petrucio Andrade Cavalcante ORCID: https://orcid.org/0000-0002-8719-7963 Universidade Federal de Campina Grande, Brasil E-mail: laertecavalcante.lc@gmail.com

Keyla Cristina Nogueira Durans ORCID: https://orcid.org/0000-0003-4963-5448

Universidade Federal do Maranhão, Brasil E-mail: keyla.durans@discente.ufma.br

Alanna Mylla Costa Leite

ORCID: https://orcid.org/0000-0002-8980-3015 Universidade Federal do Maranhão, Brasil E-mail: alannamylla70@gmail.com

Aline Ferreira Miranda

ORCID: https://orcid.org/0000-0003-1838-9360 Universidade Federal do Maranhão, Brasil E-mail: aline.miranda@discente.ufma.br

Erick Mateus Rodrigues Barbosa

ORCID: https://orcid.org/0000-0001-9035-4758

Universidade Federal do Maranhão, Brasil E-mail: erickmateus.rodrig@gmail.com

Heloísa Ferreira de Sousa

ORCID: https://orcid.org/0000-0001-7076-5314 Universidade Federal do Maranhão, Brasil

E-mail: heloisa.fs@discente.ufma.br

Juliana Lage Yule Mafra

ORCID: https://orcid.org/0000-0001-8500-4980 Universidade Federal do Maranhão, Brasil

E-mail: julianayulelm@gmail.com

Julyana Suelen Rodrigues Fonseca

ORCID: https://orcid.org/0000-0002-7777-7681

Universidade Federal do Maranhão, Brasil

E-mail: julyana.fonseca@discente.ufma.br

Lilian Karen Meneses Ferreira

ORCID: https://orcid.org/0000-0002-2245-3786

Universidade Federal do Maranhão, Brasil E-mail:1kmeneses19@gmail.com

Rafaelle Dias Estrela

ORCID: https://orcid.org/0000-0003-2274-8629

Universidade Federal do Maranhão, Brasil E-mail: rafaellediasestrela5@gmail.com

Vitor Douglas Pereira de Castro ORCID: https://orcid.org/0000-0002-2706-8609

Universidade Federal do Maranhão, Brasil E-mail: vitor.castro@discente.ufma.br

Gabriella Hellen Araújo de Oliveira ORCID: https://orcid.org/0000-0001-9145-4187 Faculdade Supremo Redentor, Brasil

E-mail: gabi.louredooliveira@hotmail.com 


\title{
Resumo
}

Introdução: O HIV, Vírus da Imunodeficiência Humana, tem se tornado uma grande pandemia e um dos mais graves problemas de saúde pública mundial. Devido a sua cronicidade, passou a ser algo com o que as pessoas necessitam conviver por toda sua vida, influenciando na qualidade de vida dessas pessoas. Objetivo: Identificar na literatura nacional informações sobre a qualidade de vida da pessoa vivendo com HIV e elencar os principais diagnósticos e intervenções de Enfermagem relacionados a melhoria da qualidade de vida desses indivíduos. Método: Revisão integrativa de literatura, com consulta nas bibliotecas e bases de dados Scientific Electronic Library Online (SciELO), Base de Dados de Enfermagem (BDENF) e Literatura Latino-Americana e do Caribe em Ciências da Saúde (LILACS), foram incluídos estudos completos que descreveram a qualidade de vida das pessoas vivendo com HIV/aids no Brasil e medidas de Enfermagem visando sua melhoria, publicados em português entre os anos de 2015 a 2021. Resultados: Foram escolhidos 24 artigos para compor os resultados. Os domínios com a QV mais afetadas a partir das falas foram: preocupação com o sigilo, relação com o meio ambiente, domínio psicológico, de independência e espiritualidade. Os diagnósticos e intervenções de enfermagem buscaram atendê-los. Considerações Finais: $\mathrm{O}$ enfermeiro deve apropriarse do Processo de Enfermagem e agir mediante as necessidades especificas de saúde do paciente no momento, fornecendo escuta ativa e acolhimento ao mesmo, sendo também promotor de ações de educação em saúde, para reduzir agravos e proporcionar maior aceitação ao diagnóstico.

Palavras-chave: Qualidade de vida; HIV; Síndrome da imunodeficiência adquirida; Diagnósticos de enfermagem.

\begin{abstract}
Introduction: HIV, Human Immunodeficiency Virus, has become a major pandemic and one of the most serious public health problems worldwide. Due to its chronicity, it has become something that people need to live with throughout their lives, influencing the quality of life of these people. Objective: To identify information in the national literature on the quality of life of people living with HIV and to list the main nursing diagnoses and interventions related to improving the quality of life of these individuals. Method: Integrative literature review, with consultation in the libraries and databases Scientific Electronic Library Online (SciELO), Nursing Database (BDENF) and Latin American and Caribbean Literature on Health Sciences (LILACS). Results: 24 articles were chosen to compose the results. The domains with the most affected QL from the speeches were: concern with confidentiality, relationship with the environment, psychological domain, independence, and spirituality. The diagnoses and nursing interventions tried to meet them. Final Considerations: The nurse should appropriate the Nursing Process and act according to the specific health needs of the patient at the time, providing active listening and welcoming, and also being a promoter of health education actions, to reduce injuries and provide greater acceptance of the diagnosis.
\end{abstract}

Keywords: Quality of life; HIV; Acquired immunodeficiency syndrome; Nursing diagnoses.

\section{Resumen}

Introducción: el VIH, virus de la inmunodeficiencia humana, se ha convertido en una importante pandemia y en uno de los problemas de salud pública más graves del mundo. Debido a su cronicidad, se ha convertido en algo con lo que hay que convivir durante toda la vida, influyendo en la calidad de vida de estas personas. Objetivo: Identificar en la literatura nacional información sobre la calidad de vida de las personas que viven con el VIH y determinar los principales diagnósticos e intervenciones de Enfermería relacionados con la mejora de la calidad de vida de estas personas. Método: Revisión bibliográfica integradora, con consulta en las bibliotecas y bases de datos Scientific Electronic Library Online (SciELO), Nursing Database (BDENF) y Latin American and Caribbean Literature on Health Sciences (LILACS). Resultados: Se eligieron un total de 24 artículos para componer los resultados. Los hogares con QV más afectados a partir de las faltas fueron: preocupación por el sigilo, relación con el medio ambiente, dominio psicológico, de independencia y espiritualidad. Los diagnósticos y las intervenciones de enfermería trataron de satisfacerlos. Consideraciones Finales: El enfermero debe apropiarse del Proceso de Enfermería y actuar según las necesidades específicas de la salud del paciente en el momento, proporcionando escuta ativa y acolhimento al mismo, siendo también promotor de acciones de educación en salud, para reducir agravios y proporcionar una mayor aceitación al diagnóstico. Palabras clave: Calidad de vida; VIH; Síndrome de inmunodeficiencia adquirida; Diagnósticos de enfermería. 


\section{Introdução}

O HIV, Vírus da Imunodeficiência Humana, tem se tornado uma grande pandemia e um dos mais graves problemas de saúde pública mundial. Segundo a Organização Mundial de Saúde (OMS), o vírus teria atingido cerca de 38 milhões de pessoas até 2019 e, desse número, 3,3 milhões são crianças menores de 15 anos (OMS, 2021). Os adultos somam 30,7 milhões, onde 14,0 milhões são homens e 16,7 milhões são mulheres e, ao contrário de tempos passados em que os homens eram os maiores infectados, atualmente as mulheres apresentam o maior número de casos de infecção (Costa et al., 2018).

A partir do ano de 1996, com o advento dos antirretrovirais, foram alcançados êxitos significativos no tratamento da pessoa que vive com HIV (PVHIV), que permitiram a redução da morbimortalidade e proporcionaram uma maior expectativa de vida aos pacientes. Devido a sua cronicidade, o HIV passou a ser algo com o que as pessoas necessitam conviver por toda sua vida, controlando-o para que sua carga viral se mantenha o mais baixo possível ou indetectável, afim de evitar também, agravos e infecções oportunistas. Entretanto, não é somente a questão medicamentosa que está presente na rotina de quem convive com o vírus. Compreender a qualidade de vida dessas pessoas está diretamente ligado à compreensão de fatores como a adesão a Terapia Antirretroviral (TARV) ou continuidade do tratamento (Foresto et al., 2017).

Possuir qualidade de vida permeia inúmeras esferas pessoais e pode ser definido, segundo a OMS como um estado de percepção da própria vida, de inserção no contexto cultural e de sistema de valores no qual se vive, e isso envolve seus objetivos, expectativas, padrões e preocupações. Sendo assim, pode-se contemplar a qualidade de vida como algo complexo que envolve o bem-estar social, físico, mental e emocional, isso além da sua interação com os outros indivíduos da comunidade, envolvendo família, amigos e relações afetivas. Adentram também as boas condições de acesso a serviços e a educação de qualidade. As maiores taxas de abandono de tratamento para o HIV estão em pessoas com menor qualidade de vida, explicitado por menor quantidade de anos estudados, condições de renda baixa que os colocavam como grupos de extrema pobreza, dentre outras situações de vulnerabilidade social (Foresto et al., 2017; Silva et al., 2019).

Apesar de todos os avanços já conquistados em relação ao entendimento sobre a infecção pelo HIV, essa condição ainda se apresenta como uma das mais estigmatizante, o que pode causar sofrimento para aqueles que têm o vírus e também para seu entorno, prejudicando a sua qualidade de vida. Além da estigmatização, fatores como preocupação com o desenvolvimento de atividades gerais, atividades sexuais, com o sigilo durante o tratamento, questões financeiras que envolvem seu cuidado, preocupações com os reflexos que a medicação pode provocar e a falta de confiança nos profissionais que acompanham sua terapia encontram-se diretamente ligados a queda da qualidade de vida, prejudicando o bom andamento do tratamento (Galvão et al., 2015).

O conceito de qualidade de vida interliga-se ao conceito ampliado de saúde e permite compreender que para se alcançar o completo bem-estar é necessário atender o indivíduo em suas mais diversas necessidades. Deste modo, proporcionar educação em saúde, suporte psicológico, permitir a criação de redes de apoio poderão atuar como diferenciais na assistência de enfermagem, permitindo a redução de fatores relacionados com a não-adesão ao tratamento como: a não aceitação do estado sorológico, a não criação de vínculo com a equipe de cuidados, as crenças e informações equivocadas acerca do tratamento, estigmas relacionados a maternidade/paternidade e o isolamento social advindo do diagnóstico (Jesus et al., 2017).

A assistência de Enfermagem, bem como seus diagnósticos e intervenções derivam das necessidades de saúde dos clientes/pacientes. Estas necessidades não se restringem apenas às questões patológicas, mas sim de todos os determinantes e condicionantes de saúde que podem estar envolvidos no processo de saúde-doença (Silva et al., 2020).

Entendendo que o diagnóstico do HIV provoca implicações que vão para além do indivíduo e refletem em seu convívio com família e sociedade, indaga-se: "Quais são as questões relacionadas à qualidade de vida da pessoa que vive com HIV e quais os principais diagnósticos e intervenções de enfermagem relacionados?’. Deste modo, o objetivo deste estudo é identificar na 
literatura nacional informações sobre a qualidade de vida da pessoa que vive com HIV e elencar os principais diagnósticos e intervenções de Enfermagem relacionados com a qualidade de vida desses indivíduos.

\section{Metodologia}

Trata-se de uma revisão da literatura na modalidade integrativa. A pergunta da pesquisa foi delimitada mediante a estratégia População Interesse Contexto (PICo) (Cardoso et al., 2019), onde, P - pessoas vivendo com HIV, I - qualidade de vida, e Co - diagnósticos e intervenções de enfermagem. Deste modo elaborou-se a seguinte pergunta norteadora: "Quais são as questões relacionadas à qualidade de vida da pessoa que vive com HIV e os principais diagnósticos e intervenções de Enfermagem associados?".

Esta pesquisa seguiu as seguintes etapas, tratadas por Souza e colaboradores, (2018): Determinou-se o tema, fazendo logo após a escolha da pergunta da pesquisa; foram definidos critérios de inclusão e exclusão; coleta ou busca em bases e bibliotecas de relevância cientifica e delimitou-se quais informações deveriam ser extraídas dos resultados. Como etapas finais, os autores interpretaram os resultados e os expuseram por meio de apresentação sintética do conhecimento.

O levantamento bibliográfico foi realizado entre os meses de maio a julho de 2021, através de consulta em bibliotecas e bases de dados relevantes para a produção do conhecimento em saúde: Scientific Electronic Library Online (SciELO), Base de Dados de Enfermagem (BDENF) e Literatura Latino-Americana e do Caribe em Ciências da Saúde (LILACS), utilizando cruzamentos com os seguintes Descritores em Ciência da Saúde (DeCS): (1) Cuidados de Enfermagem/Nursing Care; (2) Diagnóstico de Enfermagem/Nursing Diagnosis; (3) Qualidade de Vida/Quality of Life; (4) HIV/HIV, (5) Síndrome de Imunodeficiência Adquirida/Acquired Immune Deficiency Syndrome. Empregaram-se os operadores booleanos AND ou OR para a combinação desses termos em todas as bases.

Como critérios de inclusão foram utilizados: estudos completos que descreveram a qualidade de vida das pessoas vivendo com HIV no Brasil e medidas de Enfermagem visando sua melhoria, contemplando pelo menos dois dos descritores no título ou resumo, publicados em português entre os anos de 2015 a 2021. Foram excluídos da amostra os artigos que não estavam disponíveis na íntegra, assim como artigos repetidos, editoriais, artigos que relatam sobre outros temas e artigos em outros idiomas, diferentes do supracitado.

Após a busca utilizando o cruzamento dos descritores, procedeu-se como primeira etapa de seleção, à leitura do resumo buscando encontrar parâmetros de consonância aos critérios de inclusão e exclusão. Logo após, aqueles que se enquadraram na temática, foram obtidos integralmente, e realizada posteriormente a leitura de maneira criteriosa, seus resultados principais foram organizados em quadro contendo as seguintes informações: autores, periódico, ano da publicação, principais resultados.

Durante a busca, foram encontrados 300 artigos que tratavam sobre a temática, seguindo as recomendações propostas pela estratégia Preferred Reporting Items for Systematic Reviews and Meta-Analyses (PRISMA) (Galvão et al., 2015), foram selecionados 24 artigos, conforme apresentado na Figura 1. 
Figura 1 - Fluxograma de seleção dos estudos mediante estratégia PRISMA. Pinheiro, MA, Brasil, 2021.

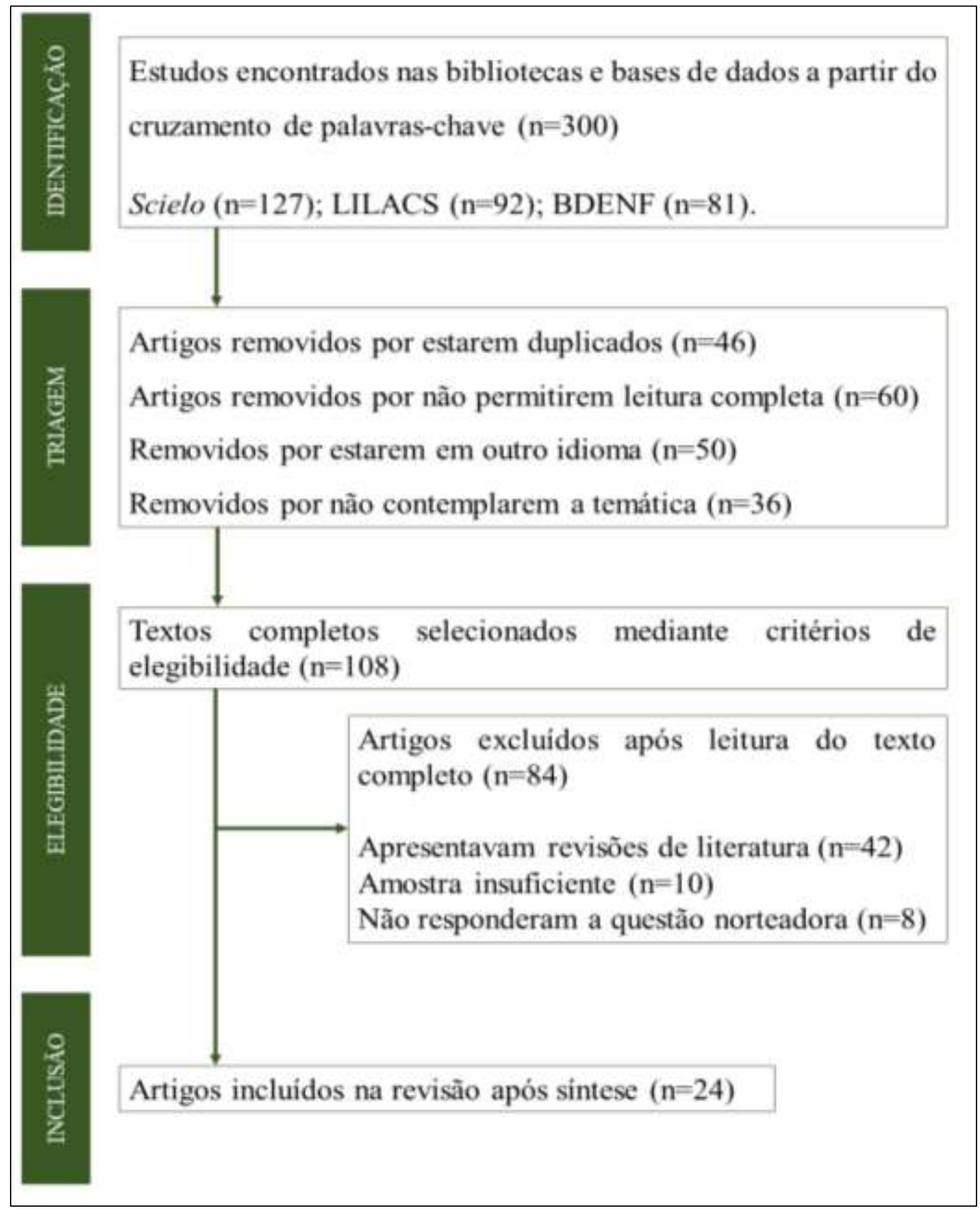

Fonte: Autores (2021).

Para correlacionar os principais diagnósticos e intervenções relacionadas à qualidade de vida do paciente com HIV encontrados nos artigos, foram consultados os livros: Diagnósticos de Enfermagem da NANDA-I: Definições e Classificação e NIC - Classificação das Intervenções de Enfermagem para organização de um quadro-síntese dos resultados encontrados (Herdman \& Kamitsuru, 2018; Butcher, 2020).

Por se tratar de uma revisão integrativa de literatura, este artigo não necessitou ser submetido à avaliação do Comitê de Ética em Pesquisa (CEP), de acordo com a resolução 466/12 do Conselho Nacional de Saúde (CNS). Apesar disso, os autores se comprometeram a respeitar e zelar pelos preceitos éticos estabelecidos pela resolução no que tange a legitimidade das informações apresentadas, privacidade e sigilo de informações caso fosse necessário e o compromisso de tornar os produtos da pesquisa públicos, por meio de publicação em periódicos de relevância cientifica. 


\section{Resultados e Discussão}

Nesta revisão foram selecionados 24 artigos, dos quais, 18 apresentaram indexação em periódicos distintos. Dois ou mais artigos foram publicados pelas revistas: Acta Paulista, Ciência \& Saúde Coletiva, Revista Brasileira de Enfermagem, Revista de Pesquisa Cuidado é Fundamental e Revista Latino-Americana de Enfermagem. Os demais periódicos apresentaram uma publicação cada a respeito do tema.

O ano com maior quantidade de publicações foi $2020(n=7)$ demonstrando o interesse cada vez mais evidente em relacionar a saúde a uma possibilidade de viver melhor, seguido do ano de 2015 (n=5) e 2019 ( $n=4)$, como evidenciado no Quadro 1.

A maior parte dos autores utilizou o instrumento World Health Organization Quality of Life (WHOQOL) HIV-bref para expor seus resultados. $O$ instrumento avalia 9 domínios que se relacionam a qualidade de vida: a função geral, satisfação com a vida, preocupações em relação a saúde, preocupações financeiras, preocupações com medicação, com o sigilo, confiança no profissional que o atenda e função sexual, respondido conforme escala do tipo Likert. Quanto menor o escore, mais afetada seria a qualidade de vida da pessoa pelo HIV. O questionário é validado e usado amplamente, tendo uma versão traduzida para o português (Fang et al., 2002).

A organização do questionário permite ligação entre as respostas dadas pelos participantes e sua associação com diagnósticos de Enfermagem, como já evidenciado em outros estudos brasileiros (Oliveira et al., 2015; Neto et al., 2019; Silva Junior et al., 2020). Os demais estudos foram realizados por meio de entrevistas, método que permite compartilhamento de experiências e vivências que não podem ser captadas pelo questionário, de abordagem quantitativa.

A partir da análise do Quadro 1, observa-se que os estudos têm mesclado as faixas etárias de avaliação, abordando desde o público infantil até o idoso e, em diferentes fases da vida, como as mulheres gravidas (Silveira et al., 2016; Caliari et al., 2018; Araújo et al., 2020; Macedo et al., 2020). Também se chama atenção às pesquisas que abordam o público LGBTQIA+, entretanto, ainda realizadas de maneira tímida (Cunha et al., 2015; Oliveira et al., 2017; Abreu et al., 2019). O conhecimento sob diferentes óticas sociais pode contribuir para uma abordagem mais direcionada pela equipe de saúde. 
Quadro 1 - Caracterização dos estudos de acordo com o ano, título, autores, periódico e principais resultados. Pinheiro, MA, Brasil, 2021.

\begin{tabular}{|c|c|c|c|c|}
\hline Ano & Titulo & Autores & Periódico & Principais resultados \\
\hline 2015 & $\begin{array}{l}\text { Qualidade de vida e fatores } \\
\text { associados } \\
\text { em pessoas vivendo com } \\
\text { HIV/AIDS }\end{array}$ & $\begin{array}{l}\text { Oliveira et } \\
\text { al. }\end{array}$ & $\begin{array}{l}\text { Acta Paulista de } \\
\text { Enfermagem }\end{array}$ & $\begin{array}{l}\text { Durante a avaliação, os domínios mais comprometidos relatados foram: o nível de independência e a relação com o meio } \\
\text { ambiente. Em análise multivariada, associaram-se positivamente a QV: maior renda, possuir ocupaçâo, ter acesso ao } \\
\text { tratamento logo após o diagnóstico. Já como fatores associados a uma pior QV estavam: ter sofrido algum tipo de } \\
\text { preconceito, relações homoafetivas e ter adquirido infecções oportunistas após o diagnóstico. }\end{array}$ \\
\hline 2015 & $\begin{array}{l}\text { Uma avaliação da qualidade } \\
\text { de vida e seus } \\
\text { determinantes nas pessoas } \\
\text { vivendo com } \\
\text { HIV/AIDS no Sul do Brasil. }\end{array}$ & $\begin{array}{l}\text { Passos e } \\
\text { Souza }\end{array}$ & $\begin{array}{c}\text { Cadernos de Saúde } \\
\text { Pública }\end{array}$ & $\begin{array}{l}\text { Idade, sexo, emprego, status socioeconômico, ter parceiro, sinais de ansiedade, sinais de depressão, suporte social, abuso } \\
\text { ou vício de substâncias psicoativas, uso de medicação antirretroviral e hospitalizações relacionadas ao HIV foram } \\
\text { independentemente associados à qualidade de vida nos domínios Ambiente, Mentalidade e Espiritualidade / Religiosidade. }\end{array}$ \\
\hline 2015 & $\begin{array}{l}\text { Qualidade de vida de } \\
\text { homens com AIDS e o } \\
\text { modelo da determinação } \\
\text { social da saúde. }\end{array}$ & Cunha et al. & $\begin{array}{l}\text { Revista Latino- } \\
\text { Americana de } \\
\text { Enfermagem }\end{array}$ & $\begin{array}{l}\text { A percepção da qualidade de vida mostrou-se intermediaria para os domínios físicos, percepção sobre a doença, nível de } \\
\text { independência e para a espiritualidade dos participantes. Por outro lado, mostrou-se positiva para as relações sociais e para } \\
\text { o domínio psicológico. Pessoas homossexuais, casadas e que não possuíam religião apresentaram percepções mais } \\
\text { negativas sobre sua qualidade de vida. }\end{array}$ \\
\hline 2015 & $\begin{array}{l}\text { Qualidade de vida de } \\
\text { crianças e adolescentes } \\
\text { infectados pelo HIV. }\end{array}$ & $\begin{array}{l}\text { Oliveira et } \\
\text { al. }\end{array}$ & $\begin{array}{c}\text { Ciência, Cuidado e } \\
\text { Saúde }\end{array}$ & $\begin{array}{l}\text { A QV foi mais afetada em relação ao domínio emocional na percepção da criança ou do adolescente, refletindo-se em } \\
\text { sentimentos de medo e ansiedade. A partir destes valores, foi possível também constatar alteração no score escolar dos } \\
\text { participantes. }\end{array}$ \\
\hline 2015 & $\begin{array}{c}\text { Qualidade de vida de } \\
\text { pessoas que vivem com } \\
\text { HIV/AIDS } \\
\text { assistidas no serviço } \\
\text { especializado em Vitória } \\
\text { (ES), Brasil }\end{array}$ & Soares et al. & $\begin{array}{c}\text { Ciência \& Saúde } \\
\text { Coletiva }\end{array}$ & $\begin{array}{l}\text { Houve associação positiva entre algumas variáveis sociodemográficas e menor qualidade de vida: ser preto ou pardo, } \\
\text { consumir bebidas alcoólicas e não possuir vínculo empregatício. Os domínios mais afetados foram: preocupação } \\
\text { financeira, preocupação com o sigilo diagnostico, manutenção das atividades sexuais e preocupação geral com a saúde. }\end{array}$ \\
\hline 2016 & $\begin{array}{l}\text { Qualidade de vida de } \\
\text { gestantes vivendo com } \\
\text { HIV/Aids }\end{array}$ & $\begin{array}{l}\text { Silveira, } \\
\text { Müller e } \\
\text { Silveira }\end{array}$ & $\begin{array}{l}\text { Revista Brasileira de } \\
\text { Ginecologia e } \\
\text { Obstetrícia }\end{array}$ & $\begin{array}{l}\text { Os escores dos domínios do questionário de qualidade de vida mais comprometidos foram a preocupação com sigilo sobre } \\
\text { a infecção, seguido de preocupações financeiras e Aceitação do HIV. O domínio com melhor escore foi preocupação com } \\
\text { a medicação. }\end{array}$ \\
\hline 2017 & $\begin{array}{l}\text { Qualidade de vida de } \\
\text { pessoas convivendo com } \\
\text { HIV/aids: relação } \\
\text { temporal, sociodemográfica } \\
\text { e perceptiva da saúde. }\end{array}$ & $\begin{array}{l}\text { Hipolito et } \\
\quad \text { al. }\end{array}$ & $\begin{array}{l}\text { Revista Latino- } \\
\text { Americana de } \\
\text { Enfermagem }\end{array}$ & $\begin{array}{l}\text { A percepção de QV não foi a mais alta para nenhum dos domínios estudados na pesquisa. Fatores como o gênero, a } \\
\text { condição econômica, orientação religiosa e tempo de diagnóstico estiveram associados a qualidade de vida, com enfoque } \\
\text { ao tempo oportuno de diagnóstico e religião como ações de enfrentamento à doença. }\end{array}$ \\
\hline 2017 & $\begin{array}{l}\text { Orientação sexual e } \\
\text { qualidade de vida de } \\
\text { pessoas vivendo com } \\
\text { HIV/AIDS. }\end{array}$ & $\begin{array}{l}\text { Oliveira et } \\
\text { al. }\end{array}$ & $\begin{array}{l}\text { Revista Brasileira de } \\
\text { Enfermagem }\end{array}$ & $\begin{array}{l}\text { Os resultados convergiram a grande presença de estigmatização e preconceito pela condição de saúde, piorado nos } \\
\text { participantes homossexuais. A qualidade de vida sofreu influência negativa do afastamento social e teve maior } \\
\text { comprometimento nos domínios de relação com o meio ambiente e nível de independência dos sujeitos. }\end{array}$ \\
\hline
\end{tabular}




\begin{tabular}{|c|c|c|c|c|}
\hline 2018 & $\begin{array}{l}\text { Representações sociais da } \\
\text { qualidade de vida de } \\
\text { pessoas que } \\
\text { vivem com HIV/AIDS }\end{array}$ & $\begin{array}{l}\text { Domingues, } \\
\text { Oliveira e } \\
\text { Marques }\end{array}$ & $\begin{array}{l}\text { Texto \& Contexto - } \\
\text { Enfermagem }\end{array}$ & $\begin{array}{l}\text { Os entrevistados consideraram a QV relacionada a aspectos biopsicossociais, sendo os principais: acesso a alimentação } \\
\text { adequada, prática regular de atividade física, acesso ao lazer. Também relacionaram a presença de "alegria" e da família } \\
\text { como elementos necessários à sua qualidade de vida. }\end{array}$ \\
\hline 2018 & $\begin{array}{l}\text { Qualidade de vida de idosos } \\
\text { vivendo com HIV/AIDS } \\
\text { em acompanhamento } \\
\text { ambulatorial }\end{array}$ & Caliari et al. & $\begin{array}{l}\text { Revista Brasileira de } \\
\text { Enfermagem }\end{array}$ & $\begin{array}{l}\text { Uma maior qualidade de vida esteve associada a variáveis sociodemográficas como o sexo dos participantes, sua condição } \\
\text { financeira, filhos, menor tempo de diagnostico, menor quantidade de efeitos colaterais a TARV, que não necessitavam de } \\
\text { ajuda para desempenhar tarefas e que não consumiam drogas. A preocupação com o sigilo sobre sua condição, bem como } \\
\text { com a sua condição financeira foram preditivos de uma má QV. }\end{array}$ \\
\hline 2019 & $\begin{array}{l}\text { Qualidade de vida de } \\
\text { mulheres transexuais com } \\
\text { HIV/AIDS }\end{array}$ & Abreu et al. & $\begin{array}{c}\text { Cogitare } \\
\text { Enfermagem }\end{array}$ & $\begin{array}{l}\text { Duas principais classes foram apontadas pelos autores mediante entrevistas: "Vulnerabilidade ao HIV/AIDS e as } \\
\text { implicações para o enfrentamento" em que as mulheres trans reforçam a estigmatização social tanto pela doença quanto } \\
\text { pela sua orientação sexual. Relatam aqui a fragilidade do vínculo com uma religião e com a sociedade de maneira geral, } \\
\text { sendo apenas a união da classe um reforço positivo a QV. Na segunda classe: "Adesão ao tratamento do HIV/AIDS e } \\
\text { contexto programático" as entrevistadas retrataram a negação da doença, adesão tardia ao tratamento e falta de inclusão } \\
\text { dentro da Atenção Primária em Saúde como empecilhos a uma qualidade de vida melhorada. }\end{array}$ \\
\hline 2019 & $\begin{array}{c}\text { Qualidade de Vida sob a } \\
\text { Ótica de Portadores de } \\
\text { HIV/AIDS: } \\
\text { Perspectivas Futuras nas } \\
\text { Práticas Educativas }\end{array}$ & Costa et al. & $\begin{array}{l}\text { Revista de Pesquisa } \\
\text { Cuidado É } \\
\text { Fundamental Online }\end{array}$ & $\begin{array}{l}\text { A análise qualitativa proporcionou o estudo de dois eixos; o primeiro relacionando o conhecimento destes e o segundo } \\
\text { trazendo as implicações na sua qualidade de vida. Os efeitos colaterais da TARV, o desconhecimento sobre as vias de } \\
\text { transmissão do HIV, a diminuição da frequência de atividade física e sexual e a necessidade constante de esconder o } \\
\text { diagnóstico para manter vínculos foram evidenciados nos discursos. }\end{array}$ \\
\hline 2019 & $\begin{array}{c}\text { Qualidade de vida de } \\
\text { pessoas vivendo com HIV } \\
\text { atendidas em serviços } \\
\text { públicos de dois municípios } \\
\text { brasileiros. }\end{array}$ & Cecílio et al. & $\begin{array}{l}\text { Revista Enfermagem } \\
\text { Uerj }\end{array}$ & $\begin{array}{l}\text { Devido a cronicidade do vírus e a convivência por grandes períodos sem a manifestação de efeitos da TARV, a maior } \\
\text { parte dos integrantes do estudo avaliou sua qualidade de vida como boa. Os principais domínios relacionados à QV pelos } \\
\text { mesmos foram o psicológico, pertencimento a uma religião ou espiritualidade, possibilidade de independência e } \\
\text { manutenção das relações sociais. }\end{array}$ \\
\hline 2019 & $\begin{array}{l}\text { Qualidade de vida no } \\
\text { contexto de pacientes com } \\
\text { HIV/AIDS: um estudo } \\
\text { comparativo }\end{array}$ & $\begin{array}{l}\text { Martins } \\
\text { Neto et al. }\end{array}$ & Saúde e Pesquisa & $\begin{array}{l}\text { Dentre os domínios estudados, o domínio Espiritualidade esteve mais associado a uma percepção positiva de qualidade } \\
\text { de vida, enquanto que o domínio Independência apresentou resultados menos positivos. }\end{array}$ \\
\hline 2020 & $\begin{array}{l}\text { Qualidade de vida dos } \\
\text { portadores de HIV/AIDS no } \\
\text { extremo norte do Brasil. }\end{array}$ & Silva et al. & $\begin{array}{l}\text { Revista Eletrônica } \\
\text { Acervo Saúde }\end{array}$ & $\begin{array}{l}\text { Uma maior qualidade de vida esteve associada a uma menor carga viral detectável e a um melhor padrão econômico. Estas } \\
\text { condições contribuíram principalmente para a melhoria do domínio psicológico de QV. }\end{array}$ \\
\hline 2020 & $\begin{array}{l}\text { Qualidade de vida, adesão e } \\
\text { indicadores clínicos em } \\
\text { pessoas vivendo com HIV. }\end{array}$ & $\begin{array}{l}\text { Primeira et } \\
\quad \text { al. }\end{array}$ & $\begin{array}{l}\text { Acta Paulista de } \\
\text { Enfermagem }\end{array}$ & $\begin{array}{l}\text { Como aspectos que interferiam diretamente na QV dos participantes de maneira positiva estavam a preocupação com o } \\
\text { estado geral de saúde, preocupação com a medicação e confiança no profissional que faz o acompanhamento. Já que como } \\
\text { fator preditivo negativo estava a preocupação com a quebra do sigilo. }\end{array}$ \\
\hline 2020 & $\begin{array}{l}\text { Qualidade de vida de } \\
\text { pessoas soropositivas: } \\
\text { relação entre situação } \\
\text { socioeconômica }\end{array}$ & $\begin{array}{c}\text { Silva } \\
\text { Junior et al. }\end{array}$ & $\begin{array}{l}\text { Revista Brasileira } \\
\text { em Promoção da } \\
\text { Saúde }\end{array}$ & $\begin{array}{l}\text { O estágio do HIV presente nos participantes não influenciou a qualidade de vida, por outro lado, a condição } \\
\text { socioeconômica apresentou-se como dificultador a uma melhor QV. As mulheres apresentaram-se como gênero mais } \\
\text { afetado. }\end{array}$ \\
\hline
\end{tabular}




\begin{tabular}{|c|c|c|c|c|}
\hline & e estágio viral. & & & \\
\hline 2020 & $\begin{array}{l}\text { Qualidade de vida das } \\
\text { pessoas que vivem com } \\
\text { HIV e suas relações } \\
\text { multifatoriais. }\end{array}$ & $\begin{array}{l}\text { Hipólito et } \\
\text { al. }\end{array}$ & $\begin{array}{l}\text { Research, Society } \\
\text { And Development }\end{array}$ & $\begin{array}{l}\text { Todos os domínios de qualidade de vida tiveram padrão intermediário, demonstrando a necessidade de acompanhamento } \\
\text { social durante a pesquisa. As áreas com QV mais afetadas foram a psicológica, relações sociais e espiritualidade, religião } \\
\text { e crenças pessoais. }\end{array}$ \\
\hline 2020 & $\begin{array}{l}\text { Qualidade de vida em } \\
\text { crianças portadoras do } \\
\text { Vírus da Imunodeficiência } \\
\quad \text { Humana (HIV) }\end{array}$ & $\begin{array}{l}\text { Macêdo et } \\
\text { al. }\end{array}$ & $\begin{array}{l}\text { Cadernos Saúde } \\
\text { Coletiva }\end{array}$ & $\begin{array}{l}\text { As crianças associaram a presença do vírus a momentos tristes de sua vida, tendo influencia na sua QV. As ações mais } \\
\text { afetadas referidas por eles foram: ficar doente, brincar sozinho e a presença de bullying na escola. Por outro lado, a } \\
\text { presença da família e a manutenção de atividades lúdicas serviram como medidas de enfretamento. }\end{array}$ \\
\hline 2020 & $\begin{array}{l}\text { Qualidade de vida em } \\
\text { indivíduos iniciando a } \\
\text { terapia antirretroviral: um } \\
\text { estudo de coorte. }\end{array}$ & $\begin{array}{l}\text { Pimentel et } \\
\text { al. }\end{array}$ & $\begin{array}{c}\text { Revista de Saúde } \\
\text { Pública }\end{array}$ & $\begin{array}{l}\text { Pessoas que realizavam o tratamento com a TARV apresentaram melhor qualidade de vida global, assim como nos } \\
\text { domínios físico, psicológico, nível de independência, ambiente e espiritual. Estar ligado a uma religião e não morar } \\
\text { sozinho também foram condições importantes a melhoria da QV. }\end{array}$ \\
\hline 2020 & $\begin{array}{c}\text { Avaliação da qualidade de } \\
\text { vida de pessoas idosas com } \\
\text { HIV } \\
\text { assistidos em serviços de } \\
\text { referência }\end{array}$ & Araújo et al. & $\begin{array}{c}\text { Ciência \& Saúde } \\
\text { Coletiva }\end{array}$ & $\begin{array}{l}\text { A QV apresentou comprometimento nos domínios: preocupação com sigilo, situação financeira e preocupação sexual. Por } \\
\text { outro lado, angustia em relação a medicação e a condição de saúde geral não interferiram na qualidade de vida dos } \\
\text { participantes. }\end{array}$ \\
\hline 2021 & $\begin{array}{l}\text { Percepções acerca da } \\
\text { qualidade de vida de } \\
\text { pessoas vivendo com HIV }\end{array}$ & $\begin{array}{l}\text { Almeida- } \\
\text { Cruz et al. }\end{array}$ & Escola Anna Nery & $\begin{array}{l}\text { Emergiram quatro classes relacionadas ao sentido de QV pelos participantes. "Dificuldades enfrentadas no tratamento" } \\
\text { em que a maior parte dos discursos retratou a dificuldade de acompanhamento médico e manutenção de peso adequado. } \\
\text { A classe } 2 \text { "Estigma e diminuição da autoestima" relacionou o preconceito e afastamento das pessoas como fator negativo } \\
\text { a qualidade de vida. Na classe } 3 \text { "Saúde como centro da QV" os participantes trouxeram depoimentos que aliavam a QV } \\
\text { a percepção ampla de saúde, envolvendo não somente aspectos clínicos, mas de interação social. Por fim, na classe } 4 \\
\text { "Viver com expectativas" as falas retratam uma esperança de melhora e possível descobrimento da cura para a AIDS. }\end{array}$ \\
\hline 2021 & $\begin{array}{c}\text { Viver com HIV/AIDS: } \\
\text { impactos do diagnóstico } \\
\text { para } \\
\text { Usuários atendidos em um } \\
\text { serviço de referência }\end{array}$ & Souza et al. & $\begin{array}{l}\text { Revista de Pesquisa } \\
\text { Cuidado É } \\
\text { Fundamental Online }\end{array}$ & $\begin{array}{l}\text { As reações diante do diagnostico como as relacionadas a tristeza, ansiedade, culpa e vontade de morrer, perda de felicidade } \\
\text { e se gratidão pela vida foram apontadas pelos participantes. Além delas, outros reflexos como diminuição da atividade } \\
\text { social e sexual, distanciamento familiar e sofrimento psicológico estiveram presentes nas falas, contribuindo } \\
\text { negativamente a QV. }\end{array}$ \\
\hline
\end{tabular}

Fonte: Autores (2021) 
Mediante leitura do Quadro 1, percebe-se que os domínios com a QV mais afetadas a partir das falas foram: preocupação com o sigilo, relação com o meio ambiente, domínio psicológico, de independência e espiritualidade. São evidenciados por falas que relatam a preocupação com a situação financeira, afastamento das atividades sociais devido a estigmatização, sentimentos de ansiedade e medo constantes, afastamento de atividades religiosas e apreensão em relação a atividades sexuais. Com base nos dados encontradas em relação aos fatores que mais afetam a QV da pessoa que vive com HIV nos artigos apresentados nos Quadro 1 e mediante consulta a NANDA e a NIC, foram elencados os principais Diagnósticos e Intervenções de Enfermagem relacionados aos resultados, sendo apresentados no Quadro 2.

Quadro 2 - Principais diagnósticos de Enfermagem e respectivas Intervenções relacionadas a melhoria da Qualidade de Vida de pacientes vivendo com HIV/, segundo a NANDA (2018) e NIC (2020). Pinheiro, MA, Brasil, 2021.

\begin{tabular}{|c|c|}
\hline DIAGNÓSTICO DE ENFERMAGEM - NANDA & INTERVENÇÃO DE ENFERMAGEM - NIC \\
\hline \multirow{6}{*}{$\begin{array}{c}\text { RISCO DE DIGNIDADE HUMANA } \\
\text { COMPROMETIDA }\end{array}$} & Apoio à Tomada de Decisão \\
\hline & Assistência em Exames \\
\hline & Intermediação Cultural \\
\hline & Orientação Antecipada \\
\hline & Orientação quanto ao Sistema de Saúde \\
\hline & Presença do profissional \\
\hline \multirow{5}{*}{ BAIXA AUTOESTIMA SITUACIONAL } & Melhoria do enfrentamento \\
\hline & Apoio à Tomada de Decisão \\
\hline & Controle do Humor \\
\hline & Facilitação do Processo de Culpa \\
\hline & Promoção de resiliência \\
\hline \multirow{3}{*}{ DESESPERANÇA } & Apoio à Tomada de Decisão \\
\hline & Apoio Emocional \\
\hline & Promoção de esperança \\
\hline \multirow{4}{*}{ RELIGIOSIDADE PREJUDICADA } & Apoio Espiritual \\
\hline & Aumento da Segurança \\
\hline & Facilitação do Crescimento Espiritual \\
\hline & Facilitação do Processo de Culpa \\
\hline \multirow{4}{*}{ RISCO DE SENTIMENTO DE IMPOTÊNCIA } & Treinamento da Assertividade \\
\hline & Melhora da Imagem Corporal \\
\hline & Redução do Estresse por Mudança \\
\hline & Promoção da Resiliência \\
\hline \multirow{3}{*}{ ESTILO DE VIDA SEDENTÁRIO } & Assistência na Automodificação \\
\hline & Ensino: Exercício Prescrito \\
\hline & Facilitação da Autorresponsabilidade \\
\hline \multirow{4}{*}{ ANSIEDADE RELACIONADA A MORTE } & Melhora do Enfrentamento \\
\hline & Apoio Emocional \\
\hline & Redução do Estresse por Mudança \\
\hline & Orientação antecipada \\
\hline \multirow{3}{*}{ PADRÃO DE SEXUALIDADE PREJUDICADA } & $\begin{array}{l}\text { Melhora da Autopercepção } \\
\text { Melhora da Imagem Corporal }\end{array}$ \\
\hline & Melhora do Enfrentamento \\
\hline & Aconselhamento \\
\hline \multirow{5}{*}{ INTERAÇÃO SOCIAL PREJUDICADA } & Melhora da Socialização \\
\hline & Melhora de Habilidades de Vida \\
\hline & Apoio Familiar \\
\hline & Escuta Ativa \\
\hline & Fortalecimento da Autoestima \\
\hline
\end{tabular}

Fonte: Herdman e Kamitsuru (2018); Butcher (2020).

A compreensão dos possíveis diagnósticos e intervenções de enfermagem à pessoa com HIV, esta intrinsecamente ligada à percepção da qualidade de vida. O conceito amplo permite ao enfermeiro direcionar o seu cuidado aos pontos de maior 
fragilidade do paciente, embasado pelo Processo de Enfermagem (PE). Foi possível observar que a maior parte dos diagnósticos esteve voltado a condições sociais e psicológicas, fato este reafirmado pelas pesquisas em que as pessoas que vivem com o vírus declararam serem excluídos do convívio com a sua família, ou terem receio de procurar lugares religiosos devido ao sentimento de culpa relacionado à doença. O HIV ainda apresenta muitos estigmas e ainda são feitas associações entre o aspecto religioso e sua infecção (Hipólito et al., 2017; Pimentel et al., 2020; Almeida-Cruz et al., 2021).

O domínio de QV e Meio Ambiente foi um dos mais afetados dentro dos estudos. As necessidades de segurança, de estabilidade financeira e moradia foram apontadas como fatores prejudiciais a qualidade de vida, pois, acarretam maiores preocupações e ambiente desfavorável ao tratamento das PVHIV (Silva et al., 2020). A baixa escolaridade pode contribuir ao abandono do tratamento devido aos efeitos colaterais proporcionados pela TARV e a situação insegura de moradia pode limitar o deslocamento do indivíduo aos locais de atendimento em saúde. O enfermeiro deve atuar além dos muros das Unidades Básicas ou áreas hospitalares, propiciando a busca ativa e encorajando a continuidade do tratamento por meio da educação em saúde (Soares et al., 2015; Domingues et al., 2018; Silva Junior et al., 2020).

A ansiedade relacionada à morte pode ser evidenciada pelos sentimentos estressantes vivenciados após o diagnóstico do HIV. Estudos retratam que ainda há considerável quantidade de falas que retratam a perda de emprego pós-diagnostico, devido ao não conhecimento adequado sobre os meios de transmissão, além do sentimento de morte evidente associada à culpa. Dentre os diagnósticos mais associados ao HIV está o de depressão, evidenciado pela falta de motivação ao desenvolvimento de atividades, tristeza e apatia constantes e a diminuição do desejo sexual devido ao medo de contaminar o parceiro. A incerteza a respeito do prognostico, aliadas a ausência de cura para a doença podem contribuir para os casos de depressão mais severa e até mesmo suicídio (Oliveira et al., 2015; Almeida-Cruz et al., 2021).

O padrão sexual prejudicado entre as PVHIV decorre do medo de infectar o parceiro ou de piora do seu próprio quadro atual, muitas vezes por desconhecimento de conceitos como os de carga viral indetectável, tempo de detecção ou dos métodos adequados para a não-transmissão do vírus, tornando os indivíduos reclusos e com maior possibilidade de solidão. Por outro lado, em outras analises também é possível perceber o padrão de negação a doença e manutenção de comportamentos de risco devido a desesperança de melhora do quadro atual e posterior (Costa et al., 2019; Primeira et al., 2020).

O ainda elevado preconceito, estigma e invisibilidade social do público LGBTQIA+ ainda os colocam em situação mais complexa em relação as atividades sexuais e inclusão nos serviços de saúde de maneira geral. Outros autores evidenciam a alta taxa de abandono entre as pessoas homossexuais, dificuldade de acesso a Atenção Primária por não adequação ao nome social e o receio de agressões físicas e verbais a partir do descobrimento do diagnóstico. Mulheres transexuais vivendo com HIV, assim como outras pessoas do grupo, necessitam aderir a profissão de prostituição para manutenção da independência financeira, pois sofrem fragilidades tanto pela sua orientação sexual quanto pelo diagnostico, que as recusa em outros locais de trabalho. $\mathrm{O}$ enfermeiro necessita oferecer reforço ao coping (enfrentamento) e também fornecer meios para o empoderamento deste público dentro dos serviços de saúde, permitindo sua aproximação e vinculo às unidades, por encontrarem nestas um ambiente acolhedor (Cunha et al., 2015; Oliveira et al., 2017; Abreu et al., 2019).

A preocupação com o sigilo profissional, realçada durante a revisão de literatura aponta todo peso social que o HIV ainda traz para os indivíduos. O medo da perda de vínculos sociais e afetivos de afastamento da rotina laboral e de julgamentos proporcionam ambiente de tensão constante e podem afasta-los dos serviços de atendimento por medo de divulgação do diagnóstico. A apreensão causada pelo descobrimento também pode refletir na recusa a manter o tratamento com a TARV, haja vista a necessidade de busca pelo mesmo, que pode ser feita em locais com identificação característica ou até mesmo pela ocorrência de efeitos colaterais fortes que não podem ser ocultados. Uma baixa adesão ao tratamento, por sua vez, contribui a maiores taxas de morbimortalidade (Passos \& Souza, 2015; Hipólito et al., 2017; Cecílio et al., 2019). 
As ações de enfermagem devem compreender os vários âmbitos que podem ser atingidos dentro da compreensão de qualidade de vida, fazendo apropriação de sua ciência para prover cuidados. A promoção de acolhimento ao cliente, escuta ativa e estimulo ao maior conhecimento sobre sua condição de saúde podem contribuir a uma maior adesão ao tratamento e minimização de angustias. A promoção de estratégias que visem maior enfrentamento às situações estressoras e que também estimulem a introdução e apoio familiar no tratamento podem contribuir para a diminuição de conflitos. É necessário ao enfermeiro um olhar singular sob cada caso para que direcione seu cuidado às reais demandas que envolvem a saúde do paciente.

A pesquisa apresentou algumas limitações que não se sobressaem a sua contribuição para o assunto. Como possíveis limitações está a não utilização de instrumento para análise dos artigos encontrados e a busca em apenas um idioma. Entretanto, pode contribuir para a caracterização da produção nacional acerca da temática e evidenciar lacunas no conhecimento que poderão ser trabalhadas por estudos posteriores.

\section{Considerações Finais}

A partir dos resultados deste estudo foi possível elucidar as principais condições que interferiram negativamente para a qualidade de vida da pessoa que vive com HIV e relacionar, a partir delas diagnósticos e intervenções de enfermagem que poderão auxiliar o profissional a guiar sua assistência de maneira mais otimizada e direcionada.

As principais alterações estiveram presentes nos domínios de independência, religiosidade e relação com o meio ambiente, reafirmando as condições de preconceito e estigmatização ainda existentes, apesar do avanço da ciência e métodos terapêuticos. Estas condições têm reflexos diretos em como o paciente se percebe diante ao mundo e influencia sua forma de se cuidar.

O enfermeiro como parte integrante da equipe de saúde deve se apoderar do Processo de Enfermagem e agir mediante as necessidades especificas de saúde do paciente no momento, fornecendo escuta ativa e acolhimento ao mesmo, sendo também promotor de ações de educação em saúde tanto na Atenção Primária quanto hospitalar, para garantir a redução de desconhecimentos sobre o agravo e maior aceitação ao diagnóstico.

\section{Referências}

Abreu, P. D. de, Araújo, E. C. de, Vasconcelos, E. M. R. de, Moura, J. W. da S., Heráclio, I. de L., Santos, Z. C. dos, \&-Santos, C. B. dos. (2019). Qualidade de vida de mulheres transexuais com hiv/aids. Cogitare Enfermagem, 24(1).

Almeida-Cruz, M. C. M. de, Castrighini, C. de C., Sousa, L. R. M., Pereira-Caldeira, N. M. V., Reis, R. K., \& Gir, E. (2021). Percepções acerca da qualidade de vida de pessoas vivendo com HIV: Artigo extraído da tese "Desenvolvimento de escala para avaliar a qualidade de vida de pessoas vivendo com HIV: Parte 2" apresentada ao Programa de Pós-Graduação em Enfermagem Fundamental da Escola de Enfermagem de Ribeirão Preto, Universidade de São Paulo, em 2019. Escola Anna Nery, 25.

Beraldo, R. A., Santos, A. P. dos, Guimarães, M. P., Vassimon, H. S., Paula, F. J. A. de, Machado, D. R. L., Foss-Freitas, M. C., \& Navarro, A. M. (2017). Redistribuição de gordura corporal e alterações no metabolismo de lipídeos e glicose em pessoas vivendo com HIV/AIDS. Revista Brasileira de Epidemiologia, $20,526-536$.

Butcher, H. K. et al. (2020). NIC - Classificação das Intervenções de Enfermagem (7a ed.). GEN Guanabara Koogan.

Caliari, J. de S., Reinato, L. A. F., Pio, D. P. M., Lopes, L. P., Reis, R. K., \& Gir, E. (2018). Quality of life of elderly people living with HIV/AIDS in outpatient follow-up. Rev. Bras. Enferm, 513-522.

Cardoso, V., Trevisan, I., Cicolella, D. de A., Waterkemper, R., Cardoso, V., Trevisan, I., Cicolella, D. de A., \& Waterkemper, R. (2019). Revisão Sistemática De Métodos Mistos: Método De Pesquisa Para A Incorporação De Evidências Na Enfermagem. Texto \& Contexto - Enfermagem, 28.

Cecilio, H. P. M., Oliveira, D. S., Marques, S. C., Apostolidis, T., \& Oliveira, D. C. (2019). Qualidade de vida de pessoas vivendo com HIV atendidas em serviços públicos de saúde. Revista Enfermagem UERJ, 27(0), 37461.

Costa, J. de M., Torres, T. S., Coelho, L. E., \& Luz, P. M. (2018). Adherence to antiretroviral therapy for HIV/AIDS in Latin America and the Caribbean: Systematic review and meta-analysis.

Costa, M. A. R., Teston, E. F., Spigolon, D. N., Dias, L. de O., \& Soares, C. de C. (2019). Qualidade de vida sob a ótica de portadores de HIV/AIDS: Perspectivas futuras nas práticas educativas. Rev. Pesqui. (Univ. Fed. Estado Rio J., Online), 1326-1332. 
Cunha, G. H. da, Fiuza, M. L. T., Gir, E., Aquino, P. de S., Pinheiro, A. K. B., \& Galvão, M. T. G. (2015). Qualidade de vida de homens com AIDS e o modelo da determinação social da saúde1. Revista Latino-Americana de Enfermagem, 23, 183-191.

Domingues, J. P., Oliveira, D. C. de, \& Marques, S. C. (2018). Representações sociais da qualidade de vida de pessoas que vivem com hiv/aids. Texto \& Contexto - Enfermagem, 27.

Fang, C.-T., Hsiung, P.-C., Yu, C.-F., Chen, M.-Y., \& Wang, J.-D. (2002). Validation of the World Health Organization quality of life instrument in patients with HIV infection. Quality of Life Research, 11(8), 753-762.

Foresto, J. S., Melo, E. S., Costa, C. R. B., Antonini, M., Gir, E., \& Reis, R. K. (2017). Adesão à terapêutica antirretroviral de pessoas vivendo com HIV/aids em um município do interior paulista. Revista Gaúcha de Enfermagem, 38.

Galvão, M. T. G., Soares, L. L., Pedrosa, S. C., Fiuza, M. L. T., \& Lemos, L. de A. (2015). Qualidade de vida e adesão à medicação antirretroviral em pessoas com HIV. Acta Paulista de Enfermagem, 28, 48-53.

Galvão, T. F., Pansani, T. de S. A., \& Harrad, D. (2015). Principais itens para relatar Revisões sistemáticas e Meta-análises: A recomendação PRISMA. Epidemiologia e Serviços de Saúde, 24, 335-342.

Hipolito, R. L., Oliveira, D. C. de, Costa, T. L. da, Marques, S. C., Pereira, E. R., \& Gomes, A. M. T. (2017). Qualidade de vida de pessoas convivendo com HIV/aids: Relação temporal, sociodemográfica e perceptiva da saúde. Revista Latino-Americana de Enfermagem, 25, 1-10.

Hipolito, R., Oliveira, D., Cecilio, H., Marques, S., Flores, P., Costa, T., \& Lima, F. (2020). Qualidade de vida das pessoas que vivem com HIV e suas relações multifatoriais. Research, Society and Development, 9, 82973749.

Herdman, T. H., \& Kamitsuru, S. (2018). Diagnósticos de Enfermagem da NANDA-I: Definições e Classificação - 2018/2020 (11a ed.). Artmed.

Jesus, G. J. de, Oliveira, L. B. de, Caliari, J. de S., Queiroz, A. A. F. L., Gir, E., \& Reis, R. K. (2017). Dificuldades do viver com HIV/Aids: Entraves na qualidade de vida. Acta Paulista de Enfermagem, 30, 301-307.

Macêdo, T. S. de, Rodrigues, M. J., Figueiredo, M. das G. F. de, \& Santos, V. E. dos. (2020). Qualidade de vida em crianças portadoras do Vírus da Imunodeficiência Humana (HIV). Cadernos Saúde Coletiva, 28, 223-230.

Neto, C. M., Pires, E. M. C., Brito, C. de S., Beserra, O. L. M. G., Junior, J. F. S., Mota, J. V., \& Caldas, R. T. J. (2019). Qualidade de vida no contexto de pacientes com hiv/aids: um estudo comparativo. Saúde e Pesquisa, 12(2), 333-341.

Oliveira, J. F. de, Oliveira, K. F. de, Zago, G. P., Weffort, V. R. S., \& Simões, A. L. de A. (2015). Qualidade de vida de crianças e adolescentes infectados pelo HIV. Ciênc. cuid. saúde, 879-884.

Oliveira, F. B. M., Moura, M. E. B., Araújo, T. M. E. de, \& Andrade, E. M. L. R. (2015). Qualidade de vida e fatores associados em pessoas vivendo com HIV/AIDS. Acta Paulista de Enfermagem, 28, 510-516.

Oliveira, F. B. M., Queiroz, A. A. F. L. N., Sousa, Á. F. L. de, Moura, M. E. B., \& Reis, R. K. (2017). Orientação sexual e qualidade de vida de pessoas vivendo com HIV/aids. Revista Brasileira de Enfermagem, 70, 1004-1010.

Organização Mundial da Saúde (2021). Dados estatísticos: HIV/AIDS nas Américas. https://www.paho.org/pt/topicos/hivaids.

Passos, S. M. K., \& Souza, L. D. de M. (2015). An evaluation of quality of life and its determinants among people living with HIV/AIDS from Southern Brazil. Cadernos de Saúde Pública, 31, 800-814.

Pimentel, G. S., Ceccato, M. das G. B., Costa, J. de O., Mendes, J. C., Bonolo, P. de F., \& Silveira, M. R. (2020). Qualidade de vida em indivíduos iniciando a terapia antirretroviral: Um estudo de coorte. Revista de Saúde Pública, 54.

Primeira, M. R., Santos, W. M. dos, Paula, C. C. de, \& Padoin, S. M. de M. (2020). Qualidade de vida, adesão e indicadores clínicos em pessoas vivendo com HIV. Acta Paulista de Enfermagem, 33.

Silva Junior, J. F., Martins Neto, C., Cardoso, B. L. A., Costa, E. M., Beserra, O. L. M. G., \& Carneiro, V. S. (2020). Qualidade de vida de pessoas soropositivas: Relação entre situação socioeconômica e estágio viral. Rev. Bras. Promoç. Saúde (Impr.), 1-10.

Silva, C. L. da, Cubas, M. R., Silva, L. L. X. da, Cabral, L. P. A., Grden, C. R. B., \& Nichiata, L. Y. I. (2019). Nursing diagnoses associated with human needs in coping with HIV. Acta Paulista de Enfermagem, 32, 18-26.

Silva, M. J. de S. e, Schraiber, L. B., \& Mota, A. (2019). O conceito de saúde na Saúde Coletiva: Contribuições a partir da crítica social e histórica da produção científica. Physis: Revista de Saúde Coletiva, 29.

Silva, M., Santos, J., Júnior, E., Marques, K., Sales, P., Costa, W., Nakashima, F., Ferreira, A., Ribeiro, L., \& Sequeira, B. (2020). Qualidade de vida dos portadores de HIV/AIDS no extremo norte do Brasil. Revista Eletrônica Acervo Saúde, e3757.

Silveira, M. P. T., Silveira, M. F., \& Müller, C. H. (2016). Quality of Life of Pregnant Women Living with HIV/AIDS. Revista Brasileira de Ginecologia e Obstetrícia, 38, 246-252.

Sousa, L. M. M. D., Firmino, C. F., Marques-Vieira, C. M. A., Severino, S. S. P., \& Pestana, H. C. F. C. (2018). Revisões da literatura científica: tipos, métodos e aplicações em enfermagem. Revista Portuguesa de Enfermagem de Reabilitação, 1(1), 45-54.

Soares, G. B., Garbin, C. A. S., Rovida, T. A. S., \& Garbin, A. J. Í. (2015). Qualidade de vida de pessoas que vivem com HIV/AIDS assistidas no serviço especializado em Vitória (ES), Brasil. Ciência \& Saúde Coletiva, 20, 1075-1084.

Souza, R. M. de, Santos, A. A. P. dos, Carvalho, A. M. A. L. de, \& Lima, V. V. R. da S. S. (2021). Viver com HIV/Aids: Impactos do diagnóstico para usuários atendidos em um serviço de referência. Rev. Pesqui. (Univ. Fed. Estado Rio J., Online), 1020-1025. 